\title{
Study on Chronic Diseases Comprehensive Intervention in Baoji of Shaanxi Province in China
}

\author{
Honglin Wang, Feng Deng*, Meng Qu, Peirong Yang, Biao Yang \\ Baoji Center for Disease Control and Prevention, Baoji, China \\ Email: ${ }^{*}$ whlxjtu@sina.com
}

Received 5 August 2014; revised 5 September 2014; accepted 5 October 2014

Copyright (C) 2014 by authors and Scientific Research Publishing Inc.

This work is licensed under the Creative Commons Attribution International License (CC BY). http://creativecommons.org/licenses/by/4.0/

(c) (i) Open Access

\section{Abstract}

Background: There is very limited data available about the epidemiology trial on chronic diseases comprehensive intervention. The aim of this study was to assess the effect of comprehensive intervention on chronic diseases in Baoji and provide basis for the improvement of chronic diseases intervention measures. Methods: Using four stages stratified random sampling method, comprehensive intervention measures were implemented on intervention group (575 individuals) respectively aimed at three crowds of whole population, high risk population and chronic diseases patients. The control group ( 782 individuals) did not receive special treatment. Two groups were evaluated effect after one year observation. Results: The chronic diseases prevalence rate of whole population in intervention group was lower than that in control group $(P<0.05)$, the blood pressure level and smoking proportion of high risk population in intervention group were lower than in control group $(P<0.05)$, and the blood pressure, blood glucose control rate of chronic diseases patients in intervention group were higher than in control group $(P<0.05)$. Conclusion: Comprehensive intervention could prevent the rise of chronic diseases prevalence. The intervention is effective in reducing or halting risk factors of high risk population, particularly in controlling blood pressure, blood glucose of patients. We should establish government leading, department cooperation, social participation, longtime and classified comprehensive intervention mechanism of chronic diseases. We believe that whole population should control the risk factors, high risk population should early diagnosis and treatment, chronic diseases patients should normalized management, and it could be applied in other counties.

\section{Keywords}

Chronic Diseases, Comprehensive Intervention, Randomized Control, Trial

\footnotetext{
${ }^{*}$ Corresponding author.
}

How to cite this paper: Wang, H.L., Deng, F., Qu, M., Yang, P.R. and Yang, B. (2014) Study on Chronic Diseases Comprehensive Intervention in Baoji of Shaanxi Province in China. Open Journal of Epidemiology, 4, 179-187. 


\section{Introduction}

With the development of society and economy, great changes have taken place in human disease spectrum pattern, population structure, lifestyle and environmental factors; chronic disease has become the main factors threatening the human health and become public health problem all over the world [1]-[3]. In recent years, government in China has taken chronic diseases prevention and control as the focus of health work, and actively constructed the chronic diseases prevention and control system covering urban and rural areas.

Domestic and international experiences show that, chronic diseases can be effectively prevented and controlled. Chronic diseases intervention for whole population can prevent and reduce the occurrence of chronic diseases, intervention for high risk population can make this part of population transfer to healthy people, and intervention for patients can control the disease progress, reduce the complications, and improve the quality of life for patients.

Comprehensive intervention research for chronic diseases has important significance for preventing and controlling chronic diseases from the long term perspective. Age, sex, culture degree, marriage, employment status and income per month are influence factors of chronic diseases KAP level [4], so we should provide targeted dietary improvement, health education, intervention techniques and measures, and policy support in view of the characteristics of the western rural areas, in order to promote the formation of healthy dietary and lifestyle for rural residents [5].

Baoji city of Shaanxi province belongs to Chinese western city, an underdeveloped area. By the end of 2012, its resident population of 3.74 million, local financial income of 6485 million yuan, the annual per capita disposable income of urban residents 25,777 yuan, per capita consumption expenditure of urban residents 17,499 yuan; per capita net income of farmers 7373 yuan, per capita consumption expenditure of farmers 5934 yuan. In 2012, a sample survey of chronic diseases in Baoji City showed that, chronic diseases prevalence rate of the city's population over 15 years was 36\% calculated and standardized according to the number of patients, and patients total medical cost per hospitalization was 5927 yuan. According to the calculation on total annual medical expenditure per patient of chronic diseases as 1000 yuan, the whole social medical expenditure due to chronic diseases was up to 1330 million yuan each year of the total city. If Baoji city can take effective intervention measures, each one percentage point falling in the chronic diseases prevalence rate, can reduce the whole medical expenditure of 37 million yuan. Therefore, to carry out comprehensive chronic diseases intervention is very urgent, and its effect is worth further study.

\section{Materials and Methods}

\subsection{Study Population}

We selected four counties (Fengxiang County, Feng County, Mei County, Qianyang County) residents as the research objects, which similar in economy, culture, customs and habits, population size, not adjacent in geographical distribution, good in organizational leadership and funding conditions in our city. Inclusion criteria: age over 15 years old, residence in Baoji city for more than six months, participated in the study voluntarily; exclusive criteria: age less than 15 years old, non residents and can't match with it. According to the administrative division, Mei County and Qianyang County were intervention groups, conducting comprehensive intervention for three population, and Fengxiang County and Feng County were control groups, no intervention measures. Age distribution and socioeconomic status of four counties is approximately representative of the overall population of Baoji.

Using four stages stratified random cluster sampling method (cluster random sampling for towns - cluster random sampling for villages and committees - systematic random sampling for households - Kish Grid method sampling for one person in each household), we extracted 80 households per village from plain counties (Fengxiang County and Mei County), 50 households per village from mountain counties (Qianyang County and Feng county) (because that mountain counties have less people), finally a total of 575 individuals in intervention group, and 782 individuals in control group. One sample village was selected from one town by cluster random sampling method in intervention and control group each other, and all the study subjects of this village were collected fasting vein blood for lipid testing, finally 130 objects in intervention and control group each other.

\subsection{Intervention Measures}

Comprehensive intervention measures were implemented on intervention group aimed at whole population, high 
risk population and chronic diseases patients respectively in three aspects of risk factors control, early diagnosis and treatment, and normalized management, in accordance with the national chronic diseases prevention and control work criterion. Risk factors control for whole population: through policy advocacy, environmental construction, technical support, health education and health promotion activities, build a healthy lifestyle supporting environment, and promote the national health lifestyle culture. High risk population: through health education, active monitoring their indexes changes, promote lifestyle self adjustment to the population with any one high risk characteristic; however, to the population with three or more high risk characteristic, they would be taken in management by medical and health institutions, regular follow-up index, carrying out intensive intervention, intervention content mainly including reasonable diet, reducing sodium intake, proper activity, alleviate psychological pressure, avoid excessive drinking. Patients with chronic diseases: detected hypertension and diabetes patients were carried out normalized management, improving the awareness rate, treatment rate and control rate, guiding the healthy lifestyle, knowing the monitoring methods of blood pressure and blood sugar, improving the compliance behavior of patients and self management ability. The control group did not receive special treatment. Two groups were evaluated effect after one year observation.

\subsection{Questionnaire Assessment Content and Analysis Index}

Questionnaire content before and after intervention consisted five parts of general situation, health status and health behavior factors, body measurement, dietary survey and blood test. Dietary survey used food frequency questionnaire, and blood test included fasting peripheral blood glucose determination, fasting blood lipid series etc. Pre intervention survey screened high risk population and high blood pressure, abnormal blood glucose patients. The main indexes assessing effect included: chronic diseases risk factors of whole population in intervention group compared with control group, comparison of five high risk characteristics between two groups, and comparison of control rate of blood pressure and blood glucose for patients between two groups.

\subsection{Diagnosis Standard}

The fasting blood glucose screening abnormal: this study used America Diabetes Association (ADA) 2012 guidelines for the diagnosis and treatment of diabetes [6], fasting blood glucose value $\geq 5.6 \mathrm{mmol} / \mathrm{L}$ as fasting blood glucose abnormal. Overweight, obesity and abdominal fat gain reference Chinese adult overweight and obesity prevention and control guide [7]: Body Mass Index (BMI) was calculated as weight divided by the square of height $\left(\mathrm{kg} / \mathrm{m}^{2}\right)$, BMI $<18.5$ as low weight, $18.5 \leq \mathrm{BMI} \leq 23.9$ as normal weight, $24.0 \leq \mathrm{BMI} \leq 27.9$ as overweight, BMI $\geq 28$ as obesity. Blood lipid: Chinese adult lipidemia prevention and control guide [8], cholesterol $(\mathrm{TC})>5.18 \mathrm{mmol} / \mathrm{L}$, high density lipoprotein cholesterol (HDL-C) $<1.04 \mathrm{mmol} / \mathrm{L}$, low density lipoprotein cholesterol $(\mathrm{LDL}-\mathrm{C})>3.37 \mathrm{mmol} / \mathrm{L}$, triglyceride $(\mathrm{TG})>1.70 \mathrm{mmol} / \mathrm{L}$, any kind of these four situations was judged as blood lipid abnormal.

Smoking: refers to continuous or cumulative smoking for six months or more, now still smokers, except for one year or more quit smoking. Passive smoking: exposure to tobacco smoke no less than one time weekly, one time no less than 15 minutes. Drinking: drinking of liquor or beer, wine, yellow wine, average one or more times weekly. High risk population of chronic diseases: defined as the presence of one following risk factors: blood pressure 130 - 139/85 - $89 \mathrm{mmHg}$, now smoker, $6.1 \leq$ fasting plasma glucose $<7.0 \mathrm{mmol} / \mathrm{L}, 5.2 \leq \mathrm{TC}<6.2$ $\mathrm{mmol} / \mathrm{L}$, waist circumference $>90 \mathrm{~cm}$ in men or $>85 \mathrm{~cm}$ in women.

\subsection{Quality Control}

We adopted methods such as training step by step, testing step by step, sending quality controllers step by step, on-site guidance and evaluation, data double entry, sampling follow-up to control quality in the research process, to ensure the quality of project investigation and data, providing basic guarantee for this study. Anthropometric measurement and blood lipid test were conducted in fasting state, using unified model measurement tools. All the collected blood samples by centrifugation were sent to Baoji city CDC in low temperature within two hours for unified detection, with automatic biochemical analyzer on four blood lipids (TG, TC, LDL-C, and HDL-C). There was some potential measure and reporting bias that could not be avoided, future two years or longer trial is warranted to verify our findings. 


\subsection{Statistical Analysis}

Epidata3.1 was used to double input data, and database was analyzed with SPSS17.0 software after check. We descript measurement data by mean + standard deviation, used $t$ test, chi-square test and ANOVA statistical test, and all analyses were performed with $P<0.05$ considered statistically significant.

\section{Results}

\subsection{Subjects Situation}

In survey objects there were 575 individuals in intervention group, male 62.26\% (358/575), female 37.74\% (217/575), mean age $45.70 \pm 15.31$; 782 individuals in control group, male 50.00\% (391/782), female 50\% (391/ 782), mean age $43.20 \pm 16.54$. According to the 5 kinds of high risk population characteristics, after intervention there were respectively $315,115,245,78,305$ individuals of high risk population in intervention group, and respectively 282, 156, 352, 88, 512 individuals in control group. After interventions there were 205, 270 individuals of hypertensive patients in two groups, and 217, 265 individuals of fasting blood glucose screening abnormal patients. In blood collection objects there were 130 individuals in intervention group, male $51.54 \%(67 / 130)$, female 48.46\% (63/130), mean age $48.11 \pm 14.11$; 130 individuals in control group, male $36.15 \%$ (47/130), female $63.85 \%$ (83/130), mean age $50.97 \pm 11.65$.

\subsection{Comparison on Risk Factors Control of Whole Population}

Prevalence rate (Table 1): In intervention group, the prevalence rate of hypertension, fasting blood glucose screening abnormal rate, LDL-C, HDL-C and total blood lipid abnormal rate were all lower than control group, and the difference above was statistically significant; there was no significant difference in TC and TG abnormal.

Chronic diseases risk factors (Table 2): The smoking rate in intervention group was lower than that in control group, the daily smoking frequency in intervention group was lower than control group (the effective number of smoking frequency data were respectively 105, 199 individuals in intervention and control group); the drinking rate in intervention group was lower than control group, the proportion of weekly drinking more than three times in intervention group was lower than control group; LDL-C level group in intervention group was lower than control group, HDL-C was higher than control group. The difference above all had statistical significance. There was no significant difference of TC and TG change level.

Food intake (Table 3): The intake of cereals, vegetables, eggs, fish, beans in intervention group was all higher than that in control group, the intake of oil and salt in intervention group was lower than control group, all with statistically significant difference; The difference of fruits, poultry meat and milk intake had no statistical significance between two groups. The intake of cereals, beans in two groups, eggs, poultry meat in intervention group reached to the requirement of Chinese residents balance diet pagoda, fruit, fish, milk did not reach the requirement, and oil and salt intake in two groups exceeded the standard.

The nutrient intake (Table 4): Average daily nutrient intake of subjects showed that, the intake of energy, protein, carbohydrate, vitamin B1, B2, B6, folic, niacin, calcium, phosphorus, potassium, magnesium, selenium in intervention group was all higher than that of control group, the intake of vitamin A and sodium was lower than control group, all with statistically significant difference; there had no significant difference in fat, vitamin C, E, iron, zinc, copper, manganese intake between two groups. The intake of proteins, carbohydrates, vitamin $\mathrm{B} 1, \mathrm{C}, \mathrm{E}$, phosphorus in two groups, energy, niacin, magnesium in intervention group reached the recommended intake requirement, the intake of vitamin A, B2, B6, folic, calcium, potassium, iron, zinc, selenium, copper, manganese in two groups did not reach the requirement, and sodium intake in two groups exceeded the standard.

Nutritional status: BMI nutritional status of two groups showed that, low weight rate of intervention group (3.3\%) was lower than that of control group (4.7\%); normal weight rate of intervention group (63.8\%) was higher than in control group (59.0\%); overweight rate of intervention group (25.4\%) was lower than in control group (29.7\%); obesity rate of intervention group (6.0\%) was lower than in control group (8.0\%).

\subsection{Control Effects of Main Index of High Risk Population}

According to the 5 kinds of high risk population characteristics, after intervention there were respectively 315 , $115,245,78,305$ individuals of high risk population in intervention group, and respectively 282, 156, 352, 88, 
Table 1. Comparison on blood pressure, blood glucose, blood lipid abnormal rate between two groups.

\begin{tabular}{|c|c|c|c|c|c|}
\hline \multicolumn{2}{|c|}{ Index } & \multirow{2}{*}{$\begin{array}{c}\text { Intervention (\%) } \\
458 \text { (79.65) }\end{array}$} & \multirow{2}{*}{$\begin{array}{l}\text { Control (\%) } \\
574(73.40)\end{array}$} & \multirow{3}{*}{$\frac{\chi^{2}}{7.11}$} & \multirow{3}{*}{$\begin{array}{c}P \\
0.008\end{array}$} \\
\hline \multirow{4}{*}{$\begin{array}{l}\text { Fasting blood glucose } \\
\text { screening }\end{array}$} & normal & & & & \\
\hline & hypertension & 117 (20.35) & 208 (26.60) & & \\
\hline & normal & 451 (78.43) & 577 (73.79) & \multirow{2}{*}{3.90} & \multirow{2}{*}{0.048} \\
\hline & abnormal & $124(21.56)$ & 205 (26.21) & & \\
\hline \multirow{2}{*}{ TC } & normal & 105 (80.77) & 95 (73.08) & \multirow{2}{*}{2.17} & \multirow{2}{*}{$>0.05$} \\
\hline & abnormal & 25 (19.23) & 35 (26.92) & & \\
\hline \multirow{2}{*}{ TG } & normal & $84(64.62)$ & $86(66.15)$ & \multirow{2}{*}{0.07} & \multirow{2}{*}{$>0.05$} \\
\hline & abnormal & $46(35.38)$ & $44(33.85)$ & & \\
\hline \multirow{2}{*}{ LDL-C } & normal & $93(71.50)$ & $51(39.20)$ & \multirow{2}{*}{27.46} & \multirow{2}{*}{$<0.05$} \\
\hline & abnormal & 37 (28.50) & $79(60.80)$ & & \\
\hline \multirow{2}{*}{ HDL-C } & normal & $83(63.80)$ & 35 (26.90) & \multirow{2}{*}{35.75} & \multirow{2}{*}{$<0.05$} \\
\hline & abnormal & $47(36.20)$ & 95 (73.10) & & \\
\hline \multirow{2}{*}{$\begin{array}{l}\text { Total blood lipid } \\
\text { abnormal rate }\end{array}$} & normal & $56(43.08)$ & 17 (13.08) & \multirow{2}{*}{28.97} & \multirow{2}{*}{$<0.05$} \\
\hline & abnormal & 74 (56.92) & 113 (86.92) & & \\
\hline
\end{tabular}

Table 2. Comparison on smoking, drinking, blood lipid between two groups.

\begin{tabular}{|c|c|c|c|c|c|}
\hline \multicolumn{2}{|c|}{ Risk factors } & Intervention (\%) & Control (\%) & $\chi^{2}$ & $P$ \\
\hline \multirow{2}{*}{ Smoking } & Yes & $105(18.26)$ & $199(25.45)$ & \multirow{2}{*}{9.845} & \multirow{2}{*}{0.002} \\
\hline & No & 470 (81.74) & $583(74.55)$ & & \\
\hline \multirow{2}{*}{ Smoking frequency } & Every day & 79 (75.24) & $176(88.44)$ & \multirow{2}{*}{11.83} & \multirow{2}{*}{0.001} \\
\hline & Occasional & $26(24.76)$ & $23(11.56)$ & & \\
\hline \multirow{2}{*}{ Drinking } & Yes & $66(11.48)$ & $124(15.86)$ & \multirow{2}{*}{5.276} & \multirow{2}{*}{0.022} \\
\hline & No & $509(88.52)$ & $658(84.14)$ & & \\
\hline \multirow{2}{*}{$\begin{array}{l}\text { Weekly drinking } \\
\text { frequency }\end{array}$} & More than three times & $42(63.64)$ & $86(69.36)$ & \multirow{2}{*}{4.82} & \multirow{2}{*}{0.028} \\
\hline & Less than three times & $24(36.36)$ & $38(30.61)$ & & \\
\hline \multicolumn{2}{|c|}{ Blood lipid } & \multicolumn{2}{|c|}{ mean + standard deviation, mmol/L } & $\mathrm{t}$ & $\mathrm{P}$ \\
\hline \multicolumn{2}{|c|}{$\mathrm{TC}$} & $4.39 \pm 0.86$ & $4.61 \pm 0.95$ & 1.77 & $>0.05$ \\
\hline \multicolumn{2}{|c|}{ TG } & $1.57 \pm 0.86$ & $1.55 \pm 0.82$ & 0.20 & $>0.05$ \\
\hline \multicolumn{2}{|c|}{ LDL-C } & $2.96 \pm 0.77$ & $3.63 \pm 0.99$ & 6.09 & $<0.05$ \\
\hline \multicolumn{2}{|c|}{ HDL-C } & $1.12 \pm 0.46$ & $0.67 \pm 0.48$ & 7.76 & $<0.05$ \\
\hline
\end{tabular}

Table 3. Comparison on average daily intake of dietary between two groups.

\begin{tabular}{ccccccc}
\hline \multirow{2}{*}{ Food } & $\begin{array}{c}\text { Recommended } \\
\text { intake }(\mathrm{g})\end{array}$ & The actual intake $(\mathrm{g})$ & $\mathrm{t}$ & $P$ \\
\cline { 3 - 5 } & $250-400$ & 467.2 & $569.1 \pm 288.0$ & $392.3 \pm 205.4$ & 12.6 & $<0.05$ \\
Cereals & 250 Average $(\mathrm{n}=1357)$ & Intervention $(\mathrm{n}=575)$ & Control $(\mathrm{n}=782)$ & & \\
Vegetables & $300-500$ & 240.8 & $270.3 \pm 206.1$ & $219.2 \pm 199.2$ & 4.6 & $<0.05$ \\
Fruits & $200-400$ & 113.7 & $109.2 \pm 152.1$ & $117.1 \pm 206.3$ & 0.8 & $>0.05$ \\
Eggs & $25-50$ & 28.5 & $31.3 \pm 32.1$ & $24.7 \pm 31.1$ & 3.8 & $<0.05$ \\
Fish & $75-100$ & 3.8 & $5.1 \pm 21.1$ & $2.1 \pm 7.5$ & 3.7 & $<0.05$ \\
Poultry meat & $50-75$ & 49.3 & $51.3 \pm 66.7$ & $46.6 \pm 55.9$ & 1.4 & $>0.05$ \\
Beans & $30-50$ & 69.3 & $85.0 \pm 90.0$ & $48.0 \pm 68.7$ & 8.6 & $<0.05$ \\
Milk & 300 & 41.5 & $44.5 \pm 81.8$ & $37.4 \pm 98.6$ & 1.4 & $>0.05$ \\
Oil & $25-30$ & 49.4 & $44.1 \pm 40.4$ & $53.4 \pm 36.8$ & 4.4 & $<0.05$ \\
Salt & $<6$ & 8.7 & $7.1 \pm 6.1$ & $9.9 \pm 8.8$ & 6.9 & $<0.05$ \\
\hline
\end{tabular}


Table 4. Comparison on average daily intake of main dietary nutrients between two groups.

\begin{tabular}{|c|c|c|c|c|c|c|}
\hline \multirow{2}{*}{ Nutrients } & \multirow{2}{*}{$\begin{array}{l}\text { Recommended } \\
\text { nutrient intake }\end{array}$} & \multicolumn{3}{|c|}{ The actual intake } & \multirow{2}{*}{$\mathrm{t}$} & \multirow{2}{*}{$P$} \\
\hline & & Average $(\mathrm{n}=1357)$ & Intervention $(\mathrm{n}=575)$ & Control $(n=782)$ & & \\
\hline Energy (kcal) & $2000-2700$ & 2070.8 & $2380.3 \pm 1159.1$ & $1843.2 \pm 828.5$ & 9.5 & $<0.05$ \\
\hline Proteins (g) & $70-80$ & 83.5 & $95.8 \pm 44.7$ & $74.4 \pm 35.2$ & 9.5 & $<0.05$ \\
\hline Fat (g) & $55.6-75$ & 43.7 & $43.5 \pm 26.6$ & $43.9 \pm 27.5$ & 0.3 & $>0.05$ \\
\hline Carbohydrates (g) & $300-405$ & 352.6 & $421.7 \pm 213.0$ & $301.9 \pm 146.3$ & 11.6 & $<0.05$ \\
\hline Vitamin A ( $\mu g R E)$ & $700-800$ & 211.9 & $167.1 \pm 152.0$ & $244.9 \pm 553.5$ & 3.7 & $<0.05$ \\
\hline Vitamin B1 (mg) & $1.3-1.4$ & 2.4 & $2.8 \pm 1.4$ & $2.0 \pm 1.1$ & 12.0 & $<0.05$ \\
\hline Vitamin B2 (mg) & $1.2-1.4$ & 0.7 & $0.7 \pm 0.4$ & $0.6 \pm 0.4$ & 2.4 & $<0.05$ \\
\hline Vitamin B6 (mg) & $1.2-1.5$ & 0.4 & $0.5 \pm 0.3$ & $0.4 \pm 0.3$ & 6.4 & $<0.05$ \\
\hline Folic $(\mu \mathrm{g})$ & 400 & 98.4 & $111.6 \pm 64.0$ & $88.7 \pm 88.3$ & 5.3 & $<0.05$ \\
\hline Niacin (mg) & $13-14$ & 11.7 & $13.5 \pm 6.7$ & $10.4 \pm 5.1$ & 9.5 & $<0.05$ \\
\hline Vitamin C (mg) & 100 & 160.6 & $151.7 \pm 217.5$ & $167.2 \pm 278.4$ & 1.2 & $>0.05$ \\
\hline Vitamin E (mg) & 14 & 15.5 & $15.2 \pm 7.9$ & $15.7 \pm 9.4$ & 1.0 & $>0.05$ \\
\hline Calcium (mg) & $800-1000$ & 420.0 & $441.2 \pm 240.6$ & $404.5 \pm 236.4$ & 2.8 & $<0.05$ \\
\hline Phosphorus (mg) & 700 & 1070.1 & $1210.8 \pm 571.4$ & $966.6 \pm 458.6$ & 8.4 & $<0.05$ \\
\hline Potassium (mg) & 2000 & 1495.9 & $1608.3 \pm 814.9$ & $1413.2 \pm 822.6$ & 4.3 & $<0.05$ \\
\hline Sodium (mg) & 2200 & 6241.3 & $5327.5 \pm 4162.5$ & $6913.2 \pm 4606.0$ & 6.6 & $<0.05$ \\
\hline Magnesium (mg) & 350 & 323.2 & $369.4 \pm 183.3$ & $289.3 \pm 156.6$ & 8.5 & $<0.05$ \\
\hline Iron (mg) & $15-20$ & 14.8 & $14.3 \pm 10.6$ & $15.1 \pm 15.7$ & 1.1 & $>0.05$ \\
\hline Zinc (mg) & $11.5-15$ & 6.6 & $6.6 \pm 3.8$ & $6.6 \pm 3.8$ & 0.2 & $>0.05$ \\
\hline Selenium $(\mu \mathrm{g})$ & 50 & 43.4 & $49.0 \pm 23.3$ & $39.3 \pm 18.7$ & 8.2 & $<0.05$ \\
\hline Copper (mg) & 2.0 & 1.3 & $1.3 \pm 0.8$ & $1.3 \pm 0.9$ & 0.5 & $>0.05$ \\
\hline Manganese (mg) & 3.5 & 2.4 & $2.3 \pm 1.5$ & $2.4 \pm 1.6$ & 0.5 & $>0.05$ \\
\hline
\end{tabular}

512 individuals in control group. After intervention, the blood pressure, smoking rate in intervention group was lower than in control group, with statistically significant difference, and there was no significant difference in other high risk characteristics (Table 5).

\subsection{Control Effects of Chronic Diseases Patients}

After interventions there were 205, 270 individuals of hypertensive patients in two groups, and 217, 265 individuals of fasting blood glucose screening abnormal patients. After intervention the control rate of blood pressure, glucose screening in intervention group was higher than in control group, with statistically significant difference (Table 6).

\section{Discussion}

Through one year's intervention control trial, we found that, chronic diseases intervention effect did not need a long time cycle as people often imagine. Research shows that, a lot of intervention measures in chronic disease prevention, such as the measures recommended in "Framework Convention on tobacco control" and combination therapy with a variety of drugs for high risk population of cardiovascular disease, were very economical and effective [9]-[11]. Moreover, the control effect usually appeared in much shorter time than expected. The latest evidence from Britain suggested that reducing smoking and exposure to secondhand smoke can quickly produce health and economic benefits, decrease cardiovascular disease rate in a short one year time, and also reduce the medical costs; in Finland, to eliminate the cause of chronic diseases risk factors after 2 to 7 years you can see significant results, even for the aged population, these measures can also take effect [12] [13]. 
Table 5. Comparison on main index of high risk population between two groups.

\begin{tabular}{|c|c|c|c|c|c|}
\hline \multicolumn{2}{|c|}{ High risk characteristics } & \multirow{2}{*}{$\begin{array}{c}\text { Intervention (\%) } \\
62 \text { (19.68) }\end{array}$} & \multirow{2}{*}{$\begin{array}{c}\text { Control (\%) } \\
76 \text { (26.95) }\end{array}$} & \multirow{3}{*}{$\begin{array}{c}\chi^{2} \\
4.422\end{array}$} & \multirow{3}{*}{$\begin{array}{c}P \\
0.035\end{array}$} \\
\hline \multirow{2}{*}{ Blood pressure } & Yes & & & & \\
\hline & No & 253 (80.32) & 206 (73.05) & & \\
\hline \multirow{2}{*}{ Smoking or not } & Yes & $21(18.26)$ & $40(25.64)$ & \multirow{2}{*}{9.845} & \multirow{2}{*}{0.002} \\
\hline & No & $94(81.74)$ & $116(74.36)$ & & \\
\hline \multirow{2}{*}{ Fasting blood glucose } & Yes & $25(10.20)$ & $48(13.64)$ & \multirow{2}{*}{1.586} & \multirow{2}{*}{0.208} \\
\hline & No & $220(89.80)$ & $304(86.36)$ & & \\
\hline \multirow{2}{*}{ Serum total cholesterol } & Yes & $18(23.08)$ & $25(28.41)$ & \multirow{2}{*}{0.613} & \multirow{2}{*}{0.434} \\
\hline & No & $60(76.92)$ & 63 (71.59) & & \\
\hline \multirow{2}{*}{ Waist circumference } & Yes & $83(27.21)$ & $148(28.91)$ & \multirow{2}{*}{0.270} & \multirow{2}{*}{0.603} \\
\hline & No & 222 (72.79) & 364 (71.09) & & \\
\hline
\end{tabular}

Table 6. Comparison on control rate of blood pressure and blood glucose between two groups.

\begin{tabular}{|c|c|c|c|c|c|}
\hline \multicolumn{2}{|c|}{ Index } & \multirow{2}{*}{$\begin{array}{c}\text { Intervention (\%) } \\
106(51.71)\end{array}$} & \multirow{2}{*}{$\begin{array}{l}\text { Control (\%) } \\
88(32.59)\end{array}$} & \multirow{3}{*}{$\frac{\chi^{2}}{17.621}$} & \multirow{3}{*}{$\begin{aligned} & P \\
& 0.05\end{aligned}$} \\
\hline Plood proccure & Controlled & & & & \\
\hline \multirow{3}{*}{$\begin{array}{l}\text { Fasting blood glucose } \\
\text { screening }\end{array}$} & Uncontrolled & 99 (48.29) & $182(67.41)$ & & \\
\hline & Controlled & 104 (47.93) & 69 (26.04) & \multirow{2}{*}{24.842} & \multirow{2}{*}{$<0.05$} \\
\hline & Uncontrolled & 113 (52.07) & 196 (73.96) & & \\
\hline
\end{tabular}

The prevalence rate of hypertension in poor women was higher [14], and the lower socio-economic status in Japanese women was their risk factor of cardiovascular disease [15]. The prevalence rate of diabetes mellitus in a higher urbanization area was higher than that in a lower area [16]. Baoji city is a heavy industry base of Shaanxi Province, is building to the Deputy Center of Guanzhong and Tianshui Economic Development Zone, with rapid urbanization, the hypertension, impaired fasting glucose, diabetes patients may have increased gradually in future, so the prevention and control of chronic diseases should be paid enough attention by the government. This study has several limitations. Firstly, there was some potential recall, measure, reporting and lost of follow up bias that could not be avoided. Secondly, one year's observe seemed a little short for some index.

In this study, the change of LDL-C, HDL-C abnormality rate and blood lipid level was most obvious, hardly of TC and TG change, it showed that the comprehensive intervention measures probably had effective shortterm effects on LDL-C, HDL-C abnormality rate and blood lipid decrease, however, effects on TC and TG will need long-term observe. We found the comprehensive intervention measures mainly by health education and healthy behavior promotion has a certain application value for lipidemia prevention and control of the city.

The intake of glutamic acid, arginine, lysine, tyrosine and cysteine from food plays an important role in hypertension [17]. Among dietary factors, carbohydrates, sodium are risk factors for hypertension, and animal protein, riboflavin, niacin, calcium, phosphorus, zinc, magnesium, potassium, animal iron [18], potassium [19] are protective factors for hypertension. In the reasonable range dietary protein intake increased or carbohydrate decreased may help control blood pressure [20]. Dietary fiber may play an important role in reducing glycated hemoglobin levels [21]. There are more and more diabetes, impaired glucose tolerance of rural residents with more total energy intake, more carbohydrates intake, less dietary fiber intake [22]. The study found that the nutrition and health status of residents in intervention group was obviously improved manifest in diet structure unreasonable situation relieved, the average daily intake of grain, vegetables, eggs, fish, beans increased, oil and salt were preliminary controlled, but still need to continue to increase the intake of fruits, fish, milk, reduce oil and salt. Normal weight rate of people increased, and low weight, overweight, obesity rate all decreased. The unreasonable dietary structure probably because the intervention measures cannot obtain ideal effect in the short term, so we should further implement the comprehensive intervention measures, in order to consolidate and improve the control effect.

The international community has achieved some consensus of a series of effective policies choice and intervention contents for chronic diseases, and this consensus is derived from different countries accumulated expe- 
rience [23] [24]. Chronic disease is closely linked with the economic and social development, chronic diseases prevention and control work has been beyond the health sector, so adopting a comprehensive and integrated action at the national level is the key to success [25]. According to the experience from home and abroad, combined with our actual, we believe that whole population should control the risk factors, high risk population should early diagnosis and treatment, chronic diseases patients should normalized management, and it could be applied in other counties. Our specific proposal is as follows: 1) health goal strategy. All levels of government, relevant departments, health system and social related aspects should cooperate closely around the core of "residential health", according to the division of their respective duties, and take comprehensive measures to prevent and control chronic diseases; 2) organization ensure strategy. Chronic diseases comprehensive prevention and control leadership team should be established at all levels of government, the principal government leaders or leaders in charge for the head of, to coordinate and solve important problems in actual work; 3) health service model transform strategy. Transform from the "treatment first" health service model to the "prevention first" model, in this regard, America and Britain have provided useful references from positive and negative aspects for China [26] [27]; 4) life cycle strategy. To gradually implement the whole life intervention strategies, mainly as the basic public health service subjects currently being implemented in China; 5) Chinese characteristics prevention and control strategies. Fully develop the health advantages of traditional Chinese medicine and Chinese traditional classical culture in effective prevention and control of chronic diseases.

\section{Conclusion}

In conclusion, comprehensive intervention could prevent the rise of chronic diseases prevalence. The intervention is effective in reducing or halting risk factors of high risk population, particularly in controlling blood pressure, blood glucose of patients. We should establish government leading, department cooperation, social participation, longtime and classified comprehensive intervention mechanism of chronic diseases throughout country as soon as possible, so as to effectively reduce their harm.

\section{Acknowledgments}

We thank the study participants for their contribution to the research, thank the guidance of Xi'an Jiao Tong University in research design, we also thank the strong support and help of Health Bureau and CDC of Baoji City and 4 counties to process in the field survey.

\section{Ethical Approval}

This work was approved by Baoji Center for Disease Control and Prevention Academic Ethics Board, and all participants gave informed consent prior to participation.

\section{Funding}

None declared.

\section{Competing Interests}

None declared.

\section{References}

[1] WHO (2002) Innovative Care for Chronic Conditions: Building Blocks for Action. WHO, Geneva.

[2] Ji, Y. (2010) Study of Chronic Diseases Epidemic Situation and the Prevention and Treatment of Countermeasure in Rural Area. Chinese General Practice, 13, 147-149.

[3] Qi, Y.Q., Wen, J.S. and Liu, C.Y. (2010) Analysis of Chronic Non Communicable Disease Epidemic Situation and Risk Factors in Baoji City of Shaanxi Province. Chinese health Education, 26, 903-905.

[4] Zhang, L., Shi, Z.F., Chi, A., et al. (2013) Analysis of Residents Chronic Diseases KAP Level and Effect Factors in 11 Years Community Intervention. Chinese Health Service Management, 10, 736-740.

[5] Bai, Y.M., Gao, R.T. and Guo, S.L. (2013) Research on the Dietary Characteristics of Rural Residents in Qinghai Province and the Importance of Chronic Diseases Prevention and Control. Chinese Journal of Prevention and Control 
of Chronic Non-Communicable Diseases, 21, 267-270.

[6] American Diabetes Association (2012) The 2012 ADA Guidelines for the Diagnosis and Treatment of Diabetes. Diabetes World·Clinical Journal, 6, 56-62.

[7] Chinese Obesity Working Group (2004) Chinese Adult Overweight and Obesity Prevention and Control Guide (Excerpt). Acta Nutrimenta Sinica, 26, 1-4.

[8] Joint Committee of Dyslipidemia Prevention Guidelines for Chinese Adult (2007) Guidelines for Chinese Adult Dyslipidemia Prevention. Chinese Journal of cardiology, 35, 390-419.

[9] Asaria, P., Chisholm, D., Mathers, C., Ezzati, M. and Beaglehole (2007) Chronic Disease Prevention: Health Effects and Financial Costs of Strategies to Reduce Salt Intake and Control Tobacco Use. Lancet, 370, 2044-2053. http://dx.doi.org/10.1016/S0140-6736(07)61698-5

[10] Lim, S.S., Gaziano, T.A., Gakidou, E., Reddy. K.S., Farzadfar, F., Lozano, R. and Rodgers, A. (2007) Prevention of Cardiovascular Disease in High-Risk Individuals in Low-Income and Middle-Income Countries: Health Effects and Costs. Lancet, 370, 2054-2062. http://dx.doi.org/10.1016/S0140-6736(07)61699-7

[11] Jamison, D.T., Breman, J.G., Measham, A.R., Alleyne, G., Claeson, M., Evans, D.B., Jha, P., Mills, A. and Musgrove, P. (2006) Disease Control Priorities in Developing Countries. Oxford University Press, New York \& World Bank, Washington DC.

[12] Sims, M., Maxwell, R., Bauld, L. and Gilmore, A. (2010) Short Terms Impact of Smoke-Free Legislation in England: Retrospective Analysis of Hospital Admissions for Myocardial Infarction. British Medical Journal, 340, c2161. http://dx.doi.org/10.1136/bmj.c2161

[13] Li, G., Zhang, P., Wang, J., Gregg, E.W., Yang, W., Gong, Q., Li, H., Jiang, Y., An, Y., Shuai, Y., Zhang, B., Zhang, J., Thompson, T., Gerzoff, R.B., Roglic, G., Hu, Y. and Bennett, P.H. (2008) The Long-Term Effect of Lifestyle Interventions to Prevent Diabetes in the China Da Qing Diabetes Prevention Study: A 20-Year Follow-Up Study. The Lancet, 371, 1783-1789. http://dx.doi.org/10.2188/jea.JE20120021

[14] Khan, R.J., Stewart, C.P., Christian, P., Schulze, K.J., Wu, L., LeClerq, S.C., et al. (2013) A Cross-Sectional Study of the Prevalence and Risk Factors for Hypertension in Rural Nepali Women. BMC Public Health, 13, 55.

[15] Fukuda, Y. and Hiyoshi, A. (2013) Associations of Household Expenditure and Marital Status with Cardiovascular Risk Factors in Japanese Adults: Analysis of Nationally Representative Surveys. Journal of Epidemiology, 23, 21-27. http://dx.doi.org/10.2188/jea.JE20120021

[16] Pan, C., Yang, W., Jia, W., Weng, J., Liu, G., Luo, B., et al. (2012) Psychological Status of Chinese Patients with Type 2 Diabetes: Data Review of Diabcare-China Studies. Diabetic Medicine, 29, 515-521. http://dx.doi.org/10.1111/j.1464-5491.2011.03436.x

[17] Kuil, W., Engberink, M.F., De Neve, M., van Rooij, F.J.A., Hofman, A., Veer, P., et al. (2013) Dietary Amino Acids and the Risk of Hypertension in a Dutch Older Population: The Rotterdam Study. American Journal of Clinical Nutrition, 97, 403-410. http://dx.doi.org/10.3945/ajcn.112.038737

[18] Wang, C., Li, Y., Kang, Z., et al. (2009) Relationship between Dietary Nutrients Intake of Obese Women with Hypertension. Chinese Public Health, 25, 751-753.

[19] Aburto, N.J., Hanson, S., Gutierrez, H., Hooper, L. and Elliott, P. (2013) Effect of Increased Potassium Intake on Cardiovascular Risk Factors and Disease: Systematic Review and Meta-Analyses. British Medical Journal, 346, f1378. http://dx.doi.org/10.1136/bmj.f1378

[20] Teunissen-Beekman, K.F. and van Baak, M.A. (2013) The Role of Dietary Protein in Blood Pressure Regulation. Current Opinion in Lipidology, 24, 65-70. http://dx.doi.org/10.1097/MOL.0b013e32835b4645

[21] He, P.S. (2012) Survey on Prevalence of Diabetes Mellitus and Its Relevancy with Nutrition Intake among Rural Residents in Junan County, 2010. Preventive Medicine Tribune, 18, 261-263.

[22] Attard, S.M., Herring, A.H., Mayer-Davis, E.J., Popkin, B.M., Meigs, J.B. and Gordon-Larsen, P. (2012) Multilevel Examination of Diabetes in Modernising China: what Elements of Urbanisation Are Most Associated with Diabetes. Diabetologia, 55, 3182-3192. http://dx.doi.org/10.1007/s00125-012-2697-8

[23] WHO (2008) Closing the Gap in a Generation: Health Equity through Action on the Social Determinants of Health. Commission on Social Determinants of Health Final Report, Geneva.

[24] Puska, P., Vartiainen, E., Laatikainen, T., Jousilahti, P. and Paavola, M. (2009) The North Karelia Project: From North Karelia to National Action. Helsinki: Helsinki University Printing House.

[25] WHO (2005) Preventing Chronic Diseases: A Vital Investment. WHO, Geneva.

[26] Woolf, S.H. and Stange, K.C. (2006) A Sense of Priorities for the Health Care Commons. American Journal of Preventive Medicine, 31, 99-102. http://dx.doi.org/10.1016/j.amepre.2006.03.010

[27] Miller, P.S. (2004) In Economics as Well as Medicine Prevention Is Better than Cure. Aged and Aging, 33, $217-218$. 
Scientific Research Publishing (SCIRP) is one of the largest Open Access journal publishers. It is currently publishing more than 200 open access, online, peer-reviewed journals covering a wide range of academic disciplines. SCIRP serves the worldwide academic communities and contributes to the progress and application of science with its publication.

Other selected journals from SCIRP are listed as below. Submit your manuscript to us via either submit@scirp.org or Online Submission Portal.
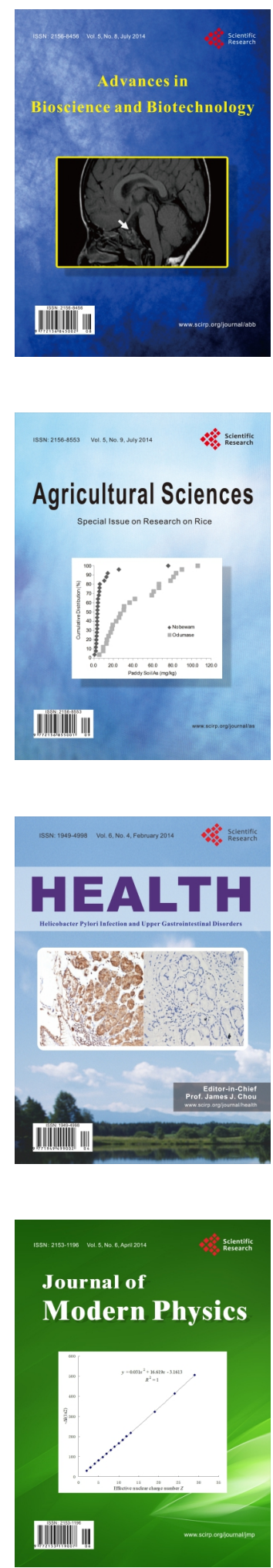
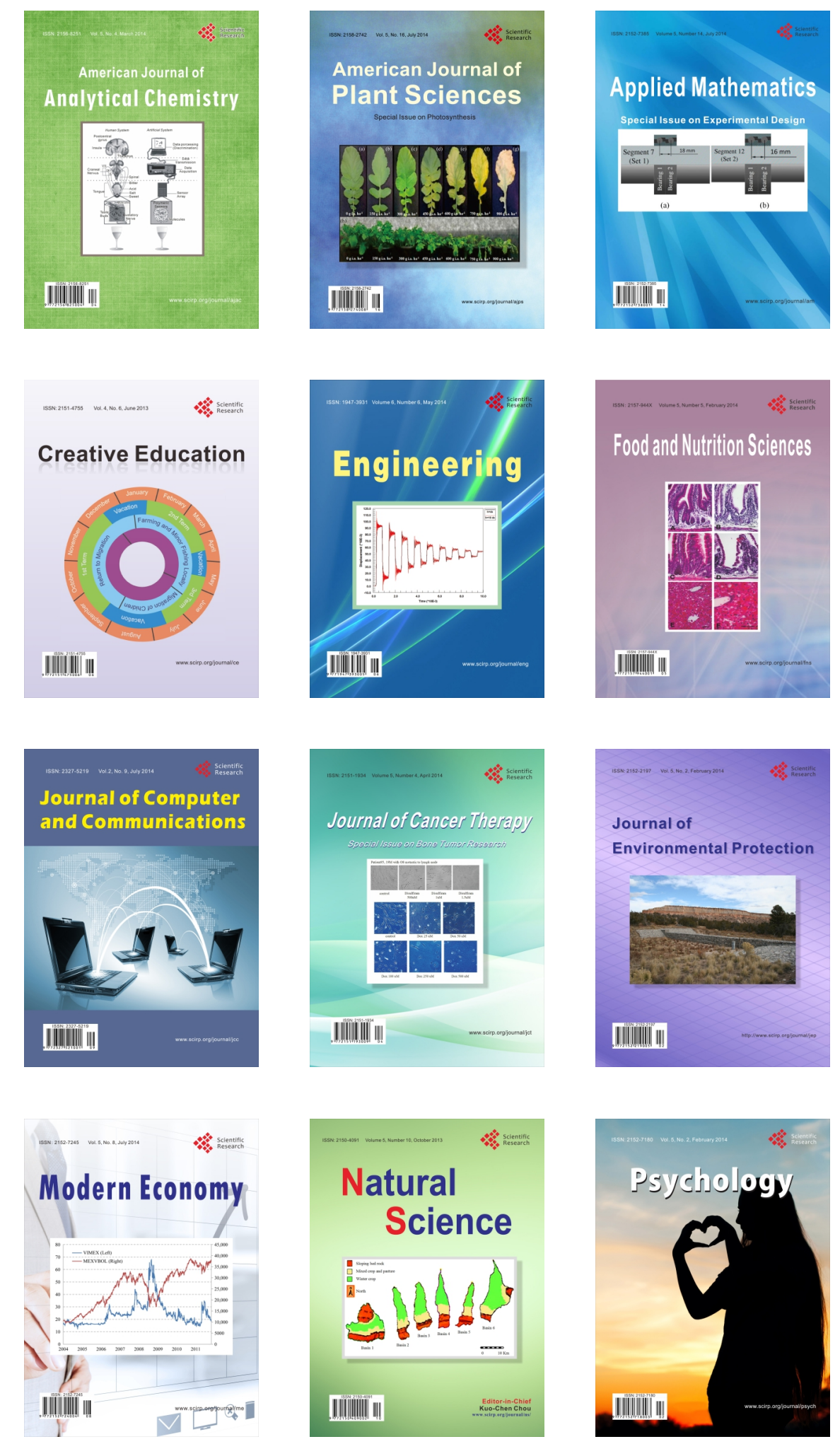